\title{
IMPLEMENTATION OF HEALTH IMPACT ASSESSMENT IN DANISH MUNICIPAL CONTEXT
}

\author{
Stella Rebecca Johnsdatter Kræmer', Louise Theilgaard Nikolajsen², Gabriel Gulis ${ }^{1}$ \\ 'Unit for Health Promotion Research, University of Southern Denmark, Esbjerg, Denmark \\ ${ }^{2}$ Disease Prevention and Health Promotion Unit, Herning Municipality, Herning, Denmark
}

\section{SUMMARY}

Aims: Implementation of Health Impact Assessment (HIA) in Danish municipalities has been analyzed using the Roger's Diffusion of Innovation Theory. Municipalities were chosen from among those who presented their health policies on websites according to the status of inclusion of HIA into health policy.

Methods: Qualitative interviews were conducted in 6 municipalities ( 3 with HIA inducted in their health policy and 3 without it) gathering information on knowledge and attitudes to HIA, barriers to its implementation, social system and communication channels used or expected to be used for implementation of HIA.

Results: No significant differences were found among analyzed municipalities by status of HIA inclusion into health policy. Among barriers, a lack of tools with general validity, a lack of intersectoral working culture, balance between centralized versus participatory way of working and organizational structure of a municipality, and a lack of capacities were enlisted as most relevant. The last one is a crucial factor of an internal social system of a municipality. With regards to communication channels, reporting and presentation skills of implementers and doers are of key importance.

Conclusions: Systematic and sustainable capacity building is needed to achieve high level implementation of HIA in Danish municipalities. Development of validated tools, most importantly screening tools with focus on priorities of national public health policy would enhance implementation on municipal level.

Key words: implementation, health impact assessment, local level

Address for correspondence: G. Gulis, Unit for Health Promotion Research, University of Southern Denmark, Niels Bohrsvej 9-10, 6700 Esbjerg, Denmark. E-mail: ggulis@health.sdu.dk

\section{INTRODUCTION}

Health Impact Assessment (HIA) has developed over the last decades from a method to assess potential future impacts of recent policies on health (1) into a process through which evidence (of different kinds), interests and values are brought to dialogue between relevant stakeholders (politicians, professionals and citizens) in order to better understand and anticipate the effects on health and health inequalities in a given population (2). Such a development signals not only a move from technical, epidemiology based exercise to a broader participatory approach based process but also an extension of the scope from predominantly environmental to wider social determinants of health. While broadening of the scope is fully justified, it poses systematic implementation of HIA into many challenges due to variability of potential stakeholders, themes, capacity, and data needs.

Implementation of HIA is largely influenced by country context. In a country with centralized governing structure HIA is most likely implemented on central, national level. If regulation based governance is preferred compared to value based one it is likely that HIA would be implemented by law with particular responsibilities for conduct. In Denmark, as a largely decentralized country, the Municipality of Nordborg (recently part of Sonderborg) in southern part of Denmark decided to use HIA in 2002, setting the baseline for implementation of HIA (3). Soon after other municipalities joined the process as well as some of the former counties (Amts) reaching about $10 \%$ of all municipalities who at certain extent used HIA in municipal work before the structural reform. The structural reform introduced by January 1st 2007 made municipalities responsible for health promotion, disease prevention and rehabilitation work and financially in charge for hospitalization costs leaving hospital management on regional level (4). It proved to be a strong facilitator of the use of HIA and increased further the number of municipalities who started at minimum to consider implementation of HIA (5). Reviewing municipal health policies developed at the time the structural reform was introduced, show that about $46 \%$ of municipalities which published their health policies on websites included HIA into methods expected to be used within municipal public health work.

The objective of this paper is to analyze how implementation of HIA is done in Denmark, what are the barriers, enablers of implementation with special emphasis on the role of social system and communication channels. Under implementation in this paper we understand the establishment of the systematic long term and sustainable use of HIA on a practical level. For the analysis we applied the Diffusion of Innovation Theory of Rogers (6) as a framework. The social system in this paper is considered as internal within municipal system. However, the external social system in a national context has an important role in implementing HIA in Denmark as well.

Besides the already mentioned structural reform a significant development could be followed also on recognition and acceptance of HIA as a method on the national level. Following the 2005 report (3) four major initiatives took place on the national 
level. In November 2008, the National Board of Health published a guidance report on HIA (7). In 2005 and 2009, there was a parliamentary debate in plenum of the Danish Parliament whether or not to implement HIA in Denmark by law $(8,9)$. In its final report in late spring 2009 the ad hoc "National disease prevention committee" included among its 52 recommendations conduct of HIA by Danish government and municipalities in all relevant national policies (10). Although this recommendation has not yet been further developed into action, it has a strong facilitating impact on implementation of HIA in Denmark.

\section{MATERIALS AND METHODS}

Qualitative interviews were conducted in six selected municipalities with both administrators and politicians during the fall of 2008. Selection of interviewees was completed via a multi-step sampling procedure as described in the following flow-chart:

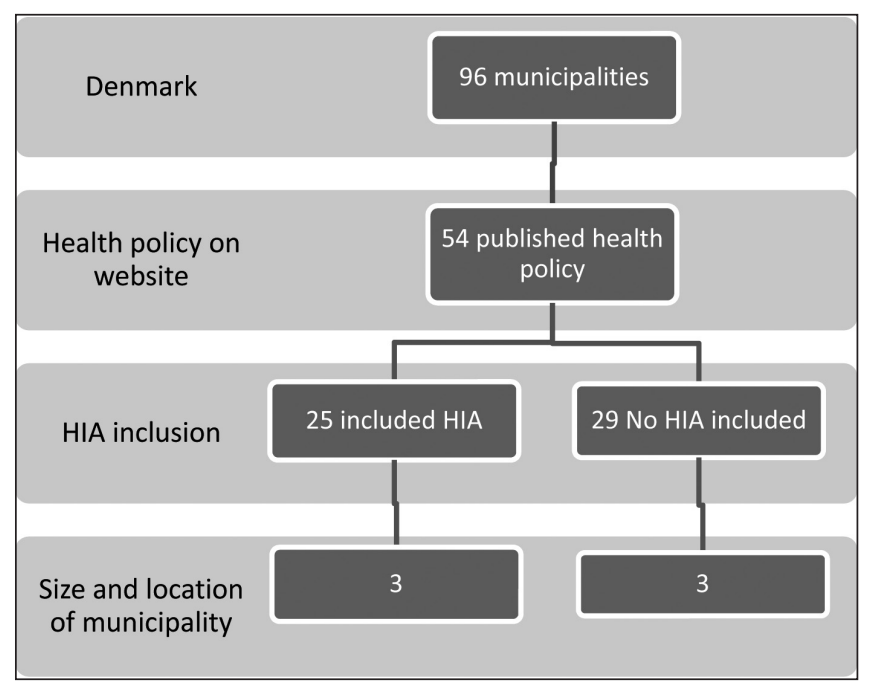

Municipal health units in each of $6(3+3)$ selected municipalities (or social care units) were contacted and with their help 2 persons per municipality were identified for interview; 1 administrator and 1 politician. A group of 12 interviewees was identified this way in the selected 6 municipalities.

A semi-structured interview guide has been developed for use containing domains on status of HIA implementation (is it planned, is it a priority, etc.), attitudes to HIA as an innovation (knowledge about HIA, personal attitudes), communication methods used for HIA implementation (how is HIA communicated across sectors, is there a "HIA champion"), the social system within municipality (values, capacities, agenda setting, etc.), and time since putting HIA on agenda.

All interviews were recorded and transcribed; the interview content was then coded using main categories of diffusion of innovation theory and after that each interview was re-read to check completeness (de-contextualization and re-contextualization).

\section{RESULTS AND DISCUSSION}

As of values and expectations toward HIA all of the municipalities declared a full agreement of basic values of municipality with values of HIA. As major expectation to HIA they reported a support to intersectoral working practices; yet one municipality claimed this is hard due to the fact that other sectors are unlikely to consider health and therefore HIA as one of their tasks. One municipality expected that HIA would directly increase physical activity in town via improved access to cycling routes and other physical activity facilities. Three municipalities expected HIA being most relevant for environment and technique department whereas two municipalities considered the social affairs department as the most relevant for conducting HIA. All 6 municipalities claimed inclusion of health impacts along with economic and environmental impacts into regular decision making process considerations.

It was expected that municipalities with HIA in health policy possess better knowledge of HIA as those not having it in their health policy; this has not been confirmed. Knowledge on HIA was mostly limited to knowledge of screening tools and individual elements of HIA rather than to HIA as a systematic process.

Table 1 summarizes attitudes to HIA as presented by interviewees; multiple responses were allowed.

In addition to presented attitudes, there were relevant and interesting comments provided by interviewees especially with regard to implementation:

- If one could provide a generally valid HIA tool that would help with implementation substantially.

- HIA is quite scientific, so hard to implement in real municipal world.

- If done, HIA should contain all steps and elements otherwise it might produce irrelevant results.

- Competent staff is needed to conduct HIA.

- It is hard to estimate how politicians will approach recommendations of completed HIA.

- It is rather the way of thinking what needs to be implemented into municipal decision making as one single method even if it is HIA.

\section{Social System and Communication}

The social system and communication channels are often closely related within the process of implementation of HIA. An example was given by one municipality describing the role of external social system which in this case was a membership of the municipality in the Danish Healthy City Network. Respondents from that municipality claimed the network being both an important social support system for implementation of HIA in municipality and also a rich communication channel. Other combined method with regard more internal social system and communication channel described by one municipality was

\section{Table 1. Attitudes of municipal policy makers to HIA}

\begin{tabular}{|l|c|}
\hline Attitudes & N \\
\hline HIA is an exciting tool to enhance intersectoral working & 2 \\
\hline HIA is perfect, at the same level as economic evaluation & 1 \\
\hline HIA is a good tool & 3 \\
\hline HIA is a good tool but alone not enough to promote health & 1 \\
\hline $\begin{array}{l}\text { HIA can contribute to development of a health promoting } \\
\text { atmosphere }\end{array}$ & 1 \\
\hline HIA introduces long-term thinking into decision making & 1 \\
\hline
\end{tabular}


organization of a "health week". That event provided a possibility to communicate information to all interested stakeholders, both public and other departments of the municipality. It also provided a strong social support for implementation of HIA or at minimum for putting implementation on the agenda. Intersectoral working groups and health policy implementation steering committees were reported as another frequent social system element and at the same time communication channels to support HIA implementation. Besides public health students on internships, consultancy service providers and national conferences all created important social system elements. Standard communication channels as websites, newsletters, project descriptions, brochures, intranet, and personnel communication were used within municipalities to disseminate information about HIA to all sectors. For social system and communication the inclusion of HIA into health policy provided a strong enabler and in fact motivation to action; the health policy itself created a major communication tool toward other non-health departments.

\section{How Far Are the Municipalities in Implementing Health Impact Assessment?}

None of the involved municipalities have implemented the full scale HIA as a standing point of agenda. In spite of the fact that 3 of these municipalities have included HIA as a goal of their health policy only one municipality have decided on an implementation plan. One municipality has after careful consideration put the implementation on hold due to the lack of resources. One municipality has after including HIA in their health policy initiated an internal dialog and discussion upon HIA. One municipality has considered HIA but does not view it as an alternative as they regard health across sectors as an implicit work. One municipality knows about HIA but has not thought about implementing it because they have many other prevention and health promotion tasks that consumes the time an implementation of HIA would take. The last municipality has HIA as a standing point of agenda but only uses it as a reflection and not a process

\section{Barriers to Implement HIA as a Cross-sector Health Initiative}

At the moment there is no agreement within municipalities that integration of health across departments is relevant. Governmental economic incentives to carry out certain types of prevention and health promotion projects were estimated to be a barrier. The municipality as an organization, its social system is considered a barrier for implementation of HIA as the municipality has a high degree of formalities in the form of fixed rules and procedures. A lack of existence of cross department procedures that HIA can be included into is a barrier given by social system of municipalities. This is often caused by a lack of attention to health from other departments. It should be highlighted that even if there is collaboration across departments it can become a barrier to a structured procedure if there is no conflict resolving mechanisms in place. Another barrier in the social system is that engagement of the politicians is not enough; there must be a clear commitment supported by allocated resources. One has to be aware that health is rarely the dominant or the only priority of political decisionmaking process. Lack of understanding of the political decision making process is often an internal barrier for HIA implementation embedded in health departments. Lack of political consensus, divergence among politicians and the public servants in relation to the political agenda, discrepancy in communication from the management and lack of availability of HIA training are further barriers in the social system regarding implementation of HIA.

An implementation of HIA in municipalities would imply a significant change of the existing rules and procedures. Generally there was a good insight on the main features of the process of HIA and what HIA can contribute to, but no one in the municipalities were confident in the detailed process of HIA. They found that HIA was a complex tool with many uncertainties.

The most important barriers to the HIA-process enlisted by interviewees were:

- Screening - a barrier to implementation of HIA is that there is no generally applicable screening tool. The subjective judgment in the screening presumes high level competence held by the one who does the screening.

- Risk appraisal - a combination of scientific literature and stakeholder perspectives (both in terms of access and understanding) often leads to methodological problems. This can undermine the validity of the assessment and represent a barrier to implementation of HIA. A lack of evidence with regard to changes in determinants of health is another barrier for implementation.

- Evaluation - there is not a generally applicable evaluation tool for HIA which is considered a barrier for the implementation of HIA. There is a focus on the essential aspect of monitoring and evaluation of HIAs that are carried out for the reason that HIA is meant to be continually refined on the basis of the experience made. Evaluation should be performed to establish the way HIA influences the decision-making process and to ascertain whether the decision to carry out the recommendations from HIA lead to an increase in health and equity in health. The missing evidence on effectiveness based on performed HIA evaluations was believed to be an important barrier in relation to implementing HIA.

- Additional barriers were found in the resources available for conduct of HIA, or rather a lack of resources (personal, financial, data, etc.). In relation to providing HIA is important that the resources assigned are harmonized with importance and scope of the policy (programme, project, plan) in question. Thus a lack of resources was viewed as a barrier for implementation.

- HIA demands a continuous support including training in determinants of health. This is viewed as a great challenge as they at several locations thought of training as a onetime investment. Furthermore, it was established that for a municipality is first of all difficult to make a general estimate of the amount of money that should be reserved for implementation and secondly it is nearly impossible to estimate how many resources are needed for future HIAs due to the diversity of policy proposals. Most of the involved municipalities thought that in the long run it would be a good investment to implement HIA that would pay off. Municipalities have emphasized that financing of HIA should be built on saved money from other prevention/health promotion areas.

In general, these findings related to implementation of HIA are very much in line with those of Finer et al. (11) and later 
confirmed by Knutsson and Linell in Sweden (12). Many of the barriers identified in this survey were described in Slovakia by Mannheimer et al. (13). Capacity building needs enlisted by interviewees are fully in compliance with those described by Hughes and Kemp in New South Wales, Australia (14).

Communication is closely related to organizational system, control and power distribution; if this is centered on one or a few persons in the municipality it could become a significant barrier to implementation of HIA. Reporting skills of those who aim to implement and conduct HIA is another important factor that influences communication. The scientific HIA process was estimated to be too complex for municipal use (6 out of 6). For that reason it was suggested that when implementing HIA, the HIA process should be carefully adjusted according to what is realistic to accomplish. It is important to guard against unrealistic expectations, illusions of total objectivity and precision in the HIA process in this way. There is a need to develop practical rather than scientific guidance for daily use of HIA.

\section{Facilitators to Implement HIA}

The basic motivation for using HIA is multifaceted. The municipalities that included HIA in their health policy were all members of the Healthy Cities Network. In literature Kearns \& Pursell (15) highlighted as a motivating factor to be a member of international organizations that are searching for new options; these findings confirm this. It was found that implementation of HIA would create the desired transversal health thinking. Implementation of HIA was additionally found to provide a common language and a pre-understanding that strengthens collaboration across the administrative structure.

Interviewees suggested strengthening inclusion of equity issues into HIA as it is a great challenge to the society. If major societal issues are clearly part or in focus of HIA, this could be a strong enabler for the implementation. As other example it has been suggested by one municipality to structure screening tool for HIA around a recent Danish public health policy priority, the so-called KRAM factors (KRAM means Kost - diet, Rygning - smoking, Alkohol - alcohol, Motion - physical activity).

\section{CONCLUSIONS}

There were no significant differences in knowledge about HIA and attitudes of interviewees based on inclusion of HIA into municipal health policy. A list of barriers to implementation has been gathered; a lack of practical generally applicable tools and methods ranks high on the list.

Organizational structure of a municipality as well as the working system (centralized versus more distributed) plays a key role in the influence of internal social system within a municipality on implementation of HIA. Membership in a larger interest network, international programme such as the Healthy City Network for example is clearly a supportive factor for implementation of HIA.
Communication skills of doers as well as implementers are major factors for successful HIA implementation. More work needs to be done on systematic and sustainable capacity building with focus on personal capacities; ad-hoc short term workshops are not enough.

\section{REFERENCES}

1. European Centre for Health Policy. Health impact assessment; main concepts and suggested approach. Gothenburg consensus paper. Brussels: European Centre for Health Policy; 1999.

2. Elliott E, Harrop E, Williams GH. Contesting the science: public health knowledge and action in controversial land-use developments. In: Bennett P, Calman K, Curtis S, Fischbacher-Smith D, editors. Risk communication and public health. 2nd ed. Oxford: Oxford University Press; 2010.

3. Bistrup ML, Kamper-Jørgensen F. Health impact assessment; concept, perspectives, use in state, district and local municipal. Copenhagen: National Institute of Public Health; 2005. (In Danish.)

4. Andersen PT, Jensen JJ. Healthcare reform in Denmark. Scand J Public Health. 2010 May;38(3):246-52.

5. Fredsgaard MW. Health impact assessment in Danish municipalities and regions - used and planned practice for health impact assessment [Internet]. Copenhagen: Healthy Cities; 2010 [cited 2014 Jul 27]. Available from: http://sund-by-net.dk/uploads/tx ttproducts/datasheet/ Sundhedskonsekvensvurdering_i_danske_kommuner_og_regioner._Anvendt_og_planlagt_praksis_for_sundhedskonsekvensvurdering_01.pdf. (In Danish.)

6. Rogers EM. Diffusion of innovation. 5th ed. New York: Free Press; 2003.

7. Gulis G, Gry P, Kræmer SRJ. Health impact assessment - from theory to practice. Copenhagen: National Board of Health; 2008.

8. The national Parliament of Denmark. B 36 Suggestion for a Parliament decision on a national strategy for fighting inequity in health [Internet]. 2005 [cited 2014 Jul 29]. Available from: http://www.ft.dk/samling/20051/ beslutningsforslag/B36/index.htm. (In Danish.)

9. The national Parliament of Denmark. B 66 Suggestion for Parliament decisions on assessments of health impacts of proposed bills [Internet]. 2009 [cited 2014 Jul 29]. Available from: http://www.ft.dk/samling/20081/ beslutningsforslag/b66/index.htm. (In Danish.)

10. The Prevention Commission. The Prevention Commission's recommendations for a strengthened preventive initiative [Internet]. Copenhagen: Ministry for Health and Prevention; 2009 [cited 2014 Jul 29]. Available from: http://www.forebyggelseskommissionen.dk/Files/Billeder/betaenkning/Forebyggelseskommissionen_rapport.pdf. (In Danish.)

11. Finer D, Tillgren P, Berensson K, Guldbrandsson K, Haglund BJ. Implementation of a Health Impact Assessment (HIA) tool in a regional health organization in Sweden - a feasibility study. Health Promot Int. 2005 Sep;20(3):277-84.

12. Knutsson I, Linell A. Health impact assessment developments in Sweden. Scand J Public Health. 2010;38(2):115-20.

13. Mannheimer LN, Gulis G, Lehto J, Ostlin P. Introducing Health Impact Assessment: an analysis of political and administrative intersectoral working methods. Eur J Public Health. 2007 Oct;17(5):526-31.

14. Hughes JL, Kemp LA. Building health impact assessment capacity as a lever for healthy public policy in urban planning. N S W Public Health Bull. 2007 Sep-Oct;18(9-10):192-4.

15. Kearns N, Pursell L. Time for a paradigm change? Tracing the institutionalisation of health impact assessment in the Republic of Ireland across health and environmental sectors. Health Policy. 2011 Feb;99(2):91-6. 